PRZEGLĄD RUSYCYSTYCZNY 2021, nr 1 (173)

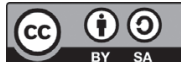

DOI 10.31261/pr.9048

\author{
ANATOLY ZAHNITKO (АНАТОЛИЙ ЗАГНИТКО) \\ Донецкий национальный университет им. Васыля Стуса \\ (D) ORCID: http://orcid.org/ 0000-0001-7398-6091
}

\title{
ФУНКЦИОНАЛЬНАЯ ПАРАДИГМА ПРЕДЛОГА
}

Майя Всеволодова, Екатерина Виноградова, Татьяна Чаплыгина, Русские предлоги и средства предложного типа. Материалы $\kappa$ функционально-грамматическому описанию реального употребления. Кн. 2: Реестр русских предложных единиц: $A-B$ (объективная грамматика), Издательство УРСС, Москва 2018

В грамматике предлог не обделён вниманием, что мотивировано его значимостью в реализации различных отношений между словами. Это легко увидеть, читая лексикографическую статью о любом предлоге. Изучение функционирования предлога является весьма сложным, поскольку необходимо определить совокупность его значений посредством изучения совокупности контекстов, это значение реализующих. Анализируемая книга является этапной и знаковой в развитии грамматического учения о предлогах с учётом системно-языкового, формально-грамматического, функционально-коммуникативного и дискурсивно-текстового аспектов. Более того, материалы представляют результат длительных дискуссий в рамках обоснованного Майей Всеволодовой международного проекта «Славянские предлоги в синхронии и диахронии: морфология и синтаксис», в котором принимали активное участие учёные из ведущих университетов Беларуси, Болгарии, Китая, России, Польши, Украины, Чехии и результатом которого стали оригинальные словари предлогов национальных языков ${ }^{1}$. Прежде чем

1 А.П. Загнітко, І.Г. Данилюк, Г.В. Ситар, А.І. Щукіна, Словник украӥнських прийменників: словник, ТОВ ВКФ „БАО”, Донецьк: 2007, с. 5-400; М. I. Канюшкевіч, Беларускія прыназоўнікі $i$ ix аналагі. Граматыка рэальнага ўжывання. Матэрыялы да слойніка, [У 3 ч.], Гродзенскі дзяржаўны універсітэт імя Янкі Купалы, Гродна 2008-2010, Ч. 1: Дыяпазон A-Л, с. 7-490; Ч. 2: Дыяпазон $M-П$, с. 11-605; Ч. 3: Дыяпазон P-Я, с. 8-331; 
рассматривать ценностные характеристики издания, следует обосновать специфику понимания предлога в интерпретации самой Майи Всеволодовой и других участников проекта.

Оригинальность всех появившихся словарей предлогов и тех, работа над которыми продолжается, обнаруживается в сочетании собственно авторского (или коллектива составителей) понимания предлогов и их эквивалентов, аналогов 1) с максимальным обобщением значения предложных единиц в рамках одной словарной статьи (словарь украинских предлогов ${ }^{2}$; 2) с последовательным дифференцированием значений предлогов и их эквивалентов в разных лексикографических статьях (словарь белорусских предлогов и их эквивалентов ${ }^{3}$ ), 3) с максимальным диагностированием всего объёма функциональной нагрузки предложных единиц и представление последних в функционально-текстовой и коммуникативно-прагматической целостности (словарь русских предлогов $\left.{ }^{4}\right)$, 4) с рассмотрением семантики предлогов с учётом особенностей их падежной синтагматики в сопоставлении анализируемых значений в национальном и русском языках 5 и т.п. Основные концептуальные подходы к толкованию и квалификации предлогов и, главное, их эквивалентов, аналогов, а также единиц, употребляемых «в значении предлога» ${ }^{6}$, представлены в серии исследований Майи Всеволодовой, Ивана Выхованца, Евгения Клобукова, Марии Конюшкевич, Ольги Кукушкиной, Чеслава Ляхура, Анатолия Поликарпова и др.

Анализирумые Русские предлоги и средства предложного типа. Материалы к функционально-грамматическому описанию реаль-

М.В. Всеволодова, О.В. Кукушкина, А.А. Поликарпов, Русские предлоги и средства предложного типа: материалы к функционально-грамматическому всего описанию реального употребления. Кн. 1: Введение в объективную граматику и лексикографию русских предложных единиц, ЛИБРОКОМ, Москва 2013, с. 6-300; Cz. Lachur, Polskie przyimki wtórne $i$ jednostki o funkcji przyimkowej $w$ użyciu realnym: materialy do stownika $(w$ zestawlieniu z językiem rosyjskim, т. 1: a conto - oprócz, Wydawnictwo NOWIK Sp.j., Opole, Kępa 2019, c. 87-425.

2 А.П. Загнітко, І.Г. Данилюк, Г. В. Ситар, А. І. Щукіна, Словник украӥнських прийменників: словник, ТОВ ВКФ „БАО”, Донецьк 2007, с. 5-400

3 М.І. Канюшкевіч, Беларускія прыназоўнікі і іх аналагі. Граматыка рэальнага ўжывання. Матэрыялы да слоўніка, [У 3 ч.], Гродзенскі дзяржаўны ўніверсітэт імя Янкі Купалы, Гродна 2008-2010, Ч. 1: Дыяпазон $A-Л$, c. 7-490; Ч. 2: Дьяпазон $M-П$, с. 11-605; Ч. 3: Дьялазон Р-Я, с. 8-331

4 М.В. Всеволодова, О.В. Кукушкина, А.А. Поликарпов, Русские предлоги и средства предложного типа..., с. 6-3оо.

5 Cz. Lachur, Polskie przyimki wtórne..., c. 87-425

6 См., например: А. П. Загнітко, К. В. Виноградова, М. В. Всеволодова та ін., Функціонально-комунікативна і текстова парадигма украйнських прийменників та їхніх еквівалентів, Вебер (Донецька філія), Донецьк 2009, с. 5-16, 22-42, 56-72. 
ного употребления. Кн. 2: Реестр русских предложных единиц: А-B (объективная грамматика) являются логическим продолжением работы научного коллектива над концептуальным осмыслением статуса предлога, его функционирования, определения доминирующих путей расширения корпуса предложных единиц, формирования переходной зоны, в пределах которой активными являются тенденции употребления слов других частей речи либо «в значении предлога», либо в «функции предлога», в предыдущих исследованиях. Говоря о грамматике вторичных предлогов, Майя Всеволодова делает ударение на необходимости создания реальной грамматики, опирающейся на концепцию объективной грамматики ${ }^{7}$, т.е. грамматику говорящего. Вполне логичными представляются размышления Всеволодовой:

Наш материал показал, что в языке речи естественного общения, в том числе в языке научных работников, журналистов и т.п., системно функционирует множество единиц, не отмеченных в наших словарях и грамматиках. Выявилось, что каждый предлог имеет несколько парадигм, что в грамматическом отношении он выполняет разные функции в рамках своей функционально-грамматической категории, а, с другой стороны, функции предлога могут выполнять и словоформы других частей речи, не выходя из своей категории. И что только представление всего материала, включая и не отмеченные в словарях и грамматиках употребления, позволят представить именно систему категории предложных единиц, которой у нас ещё у нас нет ${ }^{8}$.

Рецензируемое издание представляет единое целое с предыдущими материалами ${ }^{9}$, концептуально определившими: а) исследование теоретических принципов описания русских предложных единиц; б) анализ операциональных методов разграничения предлогов и их эквивалентов; в) выявление предложных единиц как функционально-грамматической системы, что обусловило мотивированный подход к толкованию немотивированных и мотивированных предлогов, с одной стороны, и их эквивалентов, с другой стороны. Разграничивая монолексемные и полилексемные предложные единицы, авторы вполне корректно утверждают, что, например, простые компаративы образуют разряд коррелятов - единиц, выполняющих функции предлога, не выходя из своей части речи ${ }^{10}$ и образуя приядерную позицию в зоне потенциальных предлогов. Компаративам свойственны сильная и слабая позиции реализации валентностей: Петя прыгнул выше Оли

7 А.М. Пешковский, Объективная и нормативная точка зрения на язык, URSS: ЛИБРОКОМ, Москва 2010, с. 86-103.

${ }_{8}^{8}$ М.В. Всеволодова, К грамматике вторичных предлогов..., s. 11-12.

9 М.В. Всеволодова, О.В. Кукушкина, А.А. Поликарпов, Русские предлоги и средства предложного типа..., с. 6-30о.

${ }^{10}$ Там же, с. 137. 


\section{и Петя прыгнул выше Оли на пять сантиметров.}

По своей структуре Русские предлоги и средства предложного типа... представляют теоретически обоснованные и надлежащим образом комментируемые упорядоченные предложные единицы в диапазоне $A-B$ с анализом семантических характеристик (логических отношений) анализируемых единиц. Авторы разграничивают: 1) временные - дименсив (как долго?), темпоратив (когда?), терминатив (за какое время?), терминатив (краткость срока выполнения действия), дистрибутив (как регулярно?), одновременность, предшествование, следование, скаляр (величина без указания направления); 2) пространственные - дименсив (пространство, полностью занятое предметом), директив-старт (откуда?), директив-финиш (куда?), локатив (где?), дистрибутив (в каких местах?), трасса, вектор, скаляр; 3) реляционные - интеробъектные, обусловленности (причинно-следственные, целевые, условные, уступительные, логического вывода), сравнения (сопоставления, сходства-различия), квантитативности (совместность / разделённость), включения / выключения отношения, а также; а) актантные (адресат, комитатив, делибератив, фабрикатив, инструментатив, отправитель, посредник, трансгрессив (результат каузации) и предикатные (атрибутив, квалитатив, квантитатив и отрицание) роли (с. 6-7).

Определение «Кн. 2» сразу же отсылает читателя к «Кн. 1» ${ }^{11}$, что вполне справедливо, поскольку именно в первой книге искушённый читатель найдёт исчерпывающее понимание предложной единицы. Последнюю представляют как составляющую часть синтаксемы, а функционирование предложной единицы - как один из фрагментов управления, рассматривая последнее как «формальный способ включения существительных в синтаксические построения ${ }^{12}$, в структурировании которых активным является участие падежных форм существительных, в том числе и именительного, в реализации присловных позиций. Такое толкование обусловило необходимость учёта объёма морфологической и синтаксической парадигм слова, поскольку каждое слово имеет набор словоформ, реально участвующих в синтаксических построениях. Именно синтаксическая парадигма охватывает и словесную форму, и словоформу, и синтаксему. Словесная форма рассматривается как «морфологическая часть речи в конъюнкции со служебныи словами»13 с высоким уровнем абстракции, ср., например, наличие в русском языке словесных форм имени ${ }^{14} c+N_{p}, c+N_{6}, c+N_{m}$, но

${ }^{11}$ Там же.

${ }^{12}$ Е. С. Скобликова, Согласование и управление в русском языке, Просвещение, Москва 1971, с. 32.

${ }_{13}^{13}$ М.В. Всеволодова, О.В. Кукушкина, А.А. Поликарпов, Русские предлоги и средства предложного типа..., с. 21.

${ }^{14}$ В конструкциях $\mathrm{c}+\mathrm{N}_{\mathrm{p}}, \mathrm{c}+\mathrm{N}_{\mathrm{B}}, \mathrm{c}+\mathrm{N}_{\mathrm{T}}$, но нет $\mathrm{c}+\mathrm{N}_{\text {д }}, \mathrm{N}_{\text {п }}$ обозначено: $\mathrm{c}-$ предлог, 
нет $c+N_{\partial}, N_{n}$, а словоформа - «это словесная форма в её конкретной лексической реализации» ${ }^{15}$. Синтаксема квалифицирована как «словоформа с учётом её категориального [...] значения и её синтаксических значений» ${ }^{16}$. Последовательный анализ позиционных и семантических типов синтаксем с учётом их частеречного выражения позволил дифференцировать мотивированное, обусловленное и немотивированное управление, что послужило достаточным основанием для разграничения семантической, формально-синтаксической и морфосинтаксической функций предложных единиц. Семантическая функция связана с конкретизацией имени в денотативной структуре высказывания: $\boldsymbol{\mu}$ юге - локатив, $\boldsymbol{\kappa}$ югу - директив-финиш, с юга - директив-старт, из муки (оладьи) - фабрикатив. Формально-синтаксическая функция соотносима с введением «имени существительного в синтаксическую структуру на правах словоформы» ${ }^{17}$.

Морфосинтаксическая функция предлога состоит в том, что он, не будучи частью морфологической формы слова, формирует [...] словоформу - синтаксическую форму слова, синтаксему, образуя с ней [...] единое целое ${ }^{18}$.

Такой подход позволил идентифицировать осложнители базовой формы предложной единицы, среди которых выделены: а) редупликаторы - совместное употребление двух синонимичных предлогов с одним припредложным словом: вбизи у моря, для ради детей, к вопросу о переезде; б) экспликаторы - первичные предлоги в постпозици к базовому слову: в цувет к платъю/с платъем - предлоги $\kappa$ и с являются экспликаторами; в) конкретизаторы - «компоненты, конкретизирующие те или иные параметры вводимой предлогом единицы»19, охватывающие в своём составе скаляры (Отойти от дома - Отойти далеко/недалеко от дома), векторы (действовать в интересах кого-либо - действовать в научных/личных интересах кого-либо), авторизаторы, или квалитативы (прошли с милю - прошли примерно с милю). Морфосинтаксическая парадигма включает также и варианты за счёт включения в её состав падежных: в противоход движения/в противоходе движению, а также числовых (в интересе/в интересах) вариантов базового слова. Семантическая

$\mathrm{N}$ - имя существительное, индексы сигнализируют о соответствующем падеже: p - родительный, д - дательный, в - винительный, т - творительный, п- предложный.

15 Там же, с. 21

${ }_{16}$ Там же, с. 22.

17 Там же, с. 54.

18 Там же.

${ }_{19}$ Там же, с. 58. 
парадигма ${ }^{20}$ содержит разные предложные единицы одной лексемы с разными конкретными значениями в пределах одной функционально-семантической категории, например, именной локативности: в пределах села - в пределы села - вне пределов села - за пределы села - за пределами села - из пределов села - около пределов села и проч.

Естественно, для реализации полноценного и аргументированного анализа предложных единиц с установлением их различных парадигм, дифференциации предлогов, аналогов, эквивалентов и определением статуса единиц, употребляемых «в значении предлога» либо в «функции предлога», необходимой является разработка соответствующих операциональных методов и методик. Для этой цели авторы используют: 1) методы определения перехода одной части речи в другую (лексико-семантический, морфологический, синтаксический, словообразовательный); 2) диагностику степени грамматикализации (обособление от слов с таким же категориальным значением, обособление от своей парадигмы, метафоризация и др.); 3) невозможность / возможность изъять из состава предложной единицы базовый компонент и проч.

Функционально-грамматическое поле предложных единиц включает ядро (употребляемые только в качестве предлогов), приядерную зону (потенциальные предлоги: в случае с Петром и в случае Петра), первую собственно периферийную (аналоги предлогов: в сосущцествование с чем, в соотнесённости с чем) и вторую периферийную (корреляты предлогов: написал более десятка статей, ехать со скоростью сто километров в час) зоны, где две периферийные зоны представляют эквиваленты предлогов ${ }^{21}$.

Рассмотрение теоретических основ системного статуса предлогов, их функционирования, а также определение путей пополнения класса предложных единиц и установление границ реализации разных типов их парадигм представило возможность спроецировать атрибуцию предложной единицы и характеристику составляющих её позиций, включающей: 1) атрибуцию предложной единицы и состав позиций; 2) синтагматику предложной единицы и формальные характеристики; 3) типы и характеристики синтаксем, формируемых предложной единицей; 4) опыт семантизации мотивированных предлогов и их эквивалентов; 5) парадигматику предложных единиц; 6) остальные позиции атрибуции; 7) употребление предложной единицы в паремиях; 8) грамматические квалификации ${ }^{22}$ и др. Обоснованная структура лексикографической статьи предложной единицы нашла своё полное подтверждение в рецензируемом издании, в котором словарное

\footnotetext{
${ }^{20}$ Там же, с. 61.

${ }^{21}$ Там же, с. 75-209.

${ }^{22}$ Там же, с. 206-255.
} 
толкование предложных единиц существенно расширено и включает: 1) заголовочное слово; 2) стилистические характеристики; 3) просодические и фонетические характеристики; 4) варианты; 5) статус единицы; 6) морфосинтаксический тип единицы; 7) степень самостоятельности предложной синтаксемы; 8) возможные позиции синтаксемы (позиции в структурно-семантической и коммуникативной организации предложения); 9) парадигматику предложной единицы - а) грамматическую; б) текстовую; в) адъективацию имени актанта; г) зависимость словопорядка в предложной синтаксеме от актуального членения предложения и др.; 10) синонимы лексические; 11) антонимы; 12) способность / неспособность к образованию союзов; 13) особенности отражения в словарях; 14) употребление в паремиях, а завершающим элементом являются иллюстрации (с. 5). Используя структуру лексикографической статьи, искушённый читатель легко идентифицирует анализируемую предложную статью, ср., например:

В ВОПРОСЕ С кем-чем $\left(\mathrm{N}_{\pi}\right)$. В вопросе с москвичами есть некоторая напряжёнка (Интернет).

Атрибуция: - 2. Системный. - 5. Предлог. - 6. Отымённый [вопрос] сост. (составной) с преп. (препозицией) немотив. (немотивированного) предл. (предлога) предлогом-экспликатором. 7. Свободная. Лимитатив. - 9.1.1. в вопросах чего - в вопросах касаемо чего - в вопросах касательно чего - в вопросах на счёт чего - в вопросах о чём - в вопросах относительно чего - в вопросах по чему - в вопросах по поводу чего - в вопросах про что - в вопросах с чем - в вопросе чего - в вопросе касаемо чего - в вопросе касательно чего - в вопросе о чём - в вопросе относительно чего - в вопросе по чему - в вопросе по поводу чего - в вопросе про что - в вопросе с чем. 13 СОШ и МАС не отм. (СОШ - С. И. Ожегов, Н. Ю. Шведова, Толковый словарь русского языка. Азъ, Москва 1992; МАС - Словарь русского языка. Т. 1-4ю Ред. А. П. Евгеньевой. Изд. 2. Русский язык, Москва 1981 - 1984) (с. 132-133).

Русские предлоги и средства предложного типа... являются оригинальным и творческим изданием. Его отличают аргументированность теоретического подхода к анализу предложных единиц, новаторский подход к характеристике не только традиционно рассматриваемых предлогов, но и отобранных эквивалентов предложных единиц. Эквивалентность в своём осмыслении всегда является сложной, поэтому столь важной и ценной представляется предложенная авторами концепция дифференцирования аналогов и коррелятов предложных единиц среди их эквивалентов, обоснования парадигматической многокомпонентности предложных единиц. Верится, что столь нужный словарь довольно скоро появится в своей целостности, исчерпывающе представив всю грамматическую систему предложных единиц русского языка. 


\section{REFERENCES}

Kanyushkevich, Maryya, Byelaruskiya prynazownikii ikh analahi. Hramatyka real'naha wzhyvannya. Materyyaly da slownika. [U 3 ch.], Grodna: Grodzenski dzyarzhawny wniversitet imya Yanki Kupaly, 2008-2010, Ch. 1: Dyyapazon A-L, Ch. 2: Dyyapazon M-P, Ch. 3: Dyyapazon R-Ya [Канюшкевіч, Марыя, Беларускія прыназойнікі $і$ іх аналагі. Граматыка рэальнага ўжывання. Матэрыялы да слоўніка. [У 3 ч.], Гродна: Гродзенскі дзяржаўны ўніверсітэт імя Янкі Купалы,2008-2010, Ч. 1: Дыяпазон А-Л, Ч. 2: Дыяпазон M-П, Ч. 3: Дыяпазон $P-Я]$,

Lachur, Czeslaw. Polskie przyimki wtórne i jednostki o funkcji przyimkowej w użyciu realnym: materialy do słownika ( $w$ zestawieniu z językiem rosyjskim). T. 1: a conto - oprócz. Opole, Kępa: Wydawnictwo NOWIK Sp.j., 2019.

Peshkovskiy, Aleksandr. Ob"ektivnaya i normativnaya tochka zreniya na yazyk. Moskva: URSS: LIBROKOM, 2010 [Пешковский, Александр. Объективная и нормативная точка зрения на язык. Москва: URSS : ЛИБРОКОМ, 2010].

Skoblikova, Ekaterina. Soglasovaniye i upravleniye v russkom yazyke. Moskva: Prosveshenie, 1971 [Скобликова, Екатерина. Согласование и управление в русском языке. Москва: Просвещение, 1971]

Vsevolodova, Mayya, "K grammatike vtorichnykh predlogov.” Czeslaw Lachur (Ed.). Polskie przyimki wtórne i jednostki o funkcji przyimkowej $w$ użyciu realnym: materialy do stownika ( $w$ zestawlieniu z językiem rosyjskim). T. 1: a conto oprócz. Opole, Kępa: Wydawnictwo NOWIK Sp.j., 2019: 11-16 [Всеволодова, Майя, “К грамматике вторичных предлогов.” // Czeslaw Lachur (Ed.). Polskie przyimki wtórne i jednostki o funkcji przyimkowej $w$ użyciu realnym: materialy do stownika ( $w$ zestawlieniu z językiem rosyjskim). T. 1: a conto - oprócz, Opole, Kępa: Wydawnictwo NOWIK Sp.j., 2019: 11-16].

Vsevolodova, Mayya and Kukushkina, Olga, Polikarpov, Anatolij. Russkie predlogi i sredstva predlozhnogo tipa: materialy $k$ funkcionalno-grammaticheskomu vsego opisaniyu realnogo upotrebleniya. Kn. 1: Vvedenie v obektivnuyu grammatiku i leksikografiyu russkih predlozhnyh edinic, Moskva: LIBROKOM, 2013 [Всеволодова, Майя, Кукушкина, Ольга, Поликарпов, Анатолий. Русские предлоги и средства предложного типа: материалы к функциональнограмматическому всего описанию реального употребления. Кн. 1: Введение в объективную грамматику и лексикографию русских предложных единиц, Москва: ЛИБРОКОМ, 2013].

Zahnitko, Anatoliy and Danyluk and Illia and Sytar, Hanna, Shchukina and Inna. Slounyk ukrainskykh pryimennykiv. Donetsk: TOV VKF „ВАO”, 2007 [Загнітко, Анатолій и Данилюк и Ілля, Ситар и Ганна и Щукіна, Інна. Словник украӥнських прийменників. Донецьк: ТОВ ВКФ „БАО”, 2007].

Zahnitko, Anatoliy and Vynohradova, Kateryna and Vsevolodova, Maiia et all. Funktsionalno-komunikatyvna i tekstova paradyhma ukrainskykh pryimennykiv ta yikhnikh ekvivalentiv. Donetsk: Veber (Donetska filiia), 2009 [Загнітко, Анатолій и Виноградова, Катерина и Всеволодова и Майя та ін. Функціонально-комунікативна і текстова парадигма украӥнських прийменників та їхніх еквівалентів. Донецьк: Вебер (Донецька філія), 2009]. 